\title{
БЕСПЕРЕВОДНОЕ ЧТЕНИЕ КАК СРЕДСТВО ОБОГАЩЕНИЯ РЕЧИ СТУДЕНТОВ-ИНОСТРАНЦЕВ
}

\section{NON-TRANSLATED READING AS A MEAN OF ENRICYING THE SPEECH OF ROREIGN STUDENTS}

\section{Danielyan}

Summary: The article is devoted to the development of speech and the formation of speech skills and abilities of foreign students when teaching Russian as a foreign language in a technical University.

The article presents examples of tasks that expand the vocabulary of foreign students. The principles of search, introductory and learning reading are considered.

The article provides examples of lexical, grammatical and syntactic exercises aimed at developing speech skills such as speaking and writing. The described task models will help foreign students to navigate better in the structure of scientific texts. The use of a set of such tasks is aimed at developing the skills of using special literature in professional activities.

Keywords: professional vocabulary, pre-text tasks, learning reading, scientific style of speech, professionally oriented texts.
Даниелян Мери Георгиевна

к.филол.н., доцент, Национальный исследовательский Московский Государственный Строительный институт daniel_mg@list.ru

Аннотация: Статья посвящена вопросу развития речи и формирования речевых навыков и умений студентов-иностранцев при обучении русскому языку как иностранному в техническом вузе.

В статье представлены примеры заданий, расширяющих словарный запас студентов-иностранцев. Рассматриваются принципы поискового, ознакомительного и изучающего чтения.

В статье даны примеры лексических, грамматических и синтаксических упражнений, направленных на развитие таких речевых навыков, как говорение и письмо. Описанные модели заданий помогут студентам-иностранцам лучше ориентироваться в структуре научных текстов. Использование комплекса подобных заданий направлено на развитие умений и навыков использования специальной литературы в профессиональной деятельности.

Ключевые слова: профессиональная лексика, предтекстовые задания, изучающее чтение, научный стиль речи, профессионально ориентированные тексты.
B опросы развития речи, формирования речевых навыков и умений находятся в центре внимания современной методики преподавания русского языка как иностранного.

Изучение профессионально ориентированных текстов занимает большое место в преподавании русского языка на первом курсе студентам-иностранцам технических вузов. Такая работа помогает будущим инженерам овладеть языком специальности и научным стилем речи в целом. Основную трудность при этом представляет приобретение навыков усвоения технической терминологии и специальной лексики. Для облегчения этого процесса необходимо регулярно заниматься на практических занятиях изучающим чтением научных и научно-популярных текстов, выполнять упражнения, содержащие профессиональную лексику.

На подготовительном факультете с иностранными учащимися проводится работа по усвоению специальной терминологии, но эта работа носит в основном познавательный, информативный характер.

В первом семестре иностранцы-первокурсники проходят корректировочный курс грамматики русского языка, состоящий из двух разделов: морфологии и синтаксиса. В морфологической части представлены темы, вызывающие наибольшее затруднения: образование и употребле- ние причастий и деепричастий. Морфологический раздел включает в себя систему упражнений, построенных на профессионально ориентированной лексике. Задачей преподавателя на этом этапе обучения является активизация специальной лексики студентов-иностранцев, применение слов-терминов в профессиональном общении. Для усвоения и запоминания профессиональной лексики на практических занятиях по русскому языку особое внимание уделяется изучающему чтению литературы по специальности. Для контроля усвоения слов-терминов используются задания, в которых пропуски должны быть заполнены соответствующими словами-терминами.

Вся эта работа направлена на снятие лексико-грамматических трудностей, так как студенты-иностранцы на лекционных занятиях понимают лишь половину того, что объясняет преподаватель-предметник. И происходит это не только из-за темпа речи лектора. Иностранные студенты затрудняются и при устных ответах на семинарах и экзаменах, так как они не владеют тем объемом лексических единиц, необходимых для полноценного монологического высказывания.

Целесообразно использовать на практических занятиях и словообразовательные упражнения. Знание и употребление словообразовательных суффиксов, образование с их помощью отглагольных имен существительных расширяют словарный запас студентов-иностранцев. 
Синтаксический раздел корректировочного курса состоит из комплекса упражнений, направленных на анализ простого и сложного предложений, а также на порядок слов, используемый в научном стиле речи. Студентам объясняется принцип определения грамматической основы предложения, как с помощью вопросов выявить группы подлежащего и сказуемого или его именной части, а также группы дополнения. Для наглядности разбираются слова и словосочетания в предложениях, определяя их синтаксическую роль в предложении.

Практические занятия во втором семестре направлены на работу с текстом профессиональной направленности, а именно, научить студентов-иностранцев технических вузов читать и понимать литературу по специальности на русском языке без использования словаря. Предлагаемые тексты могут быть взяты не только из учебных пособий, но и из профессиональных журналов, а также может быть привлечена научно-популярная литература. Изучающее чтение без применения перевода направлена на усвоение, запоминание и применение профессиональной лексики в учебно-профессиональной сфере общения студентов-иностранцев, а также на умение строить монологические неподготовленные высказывания на профессиональные темы.

Используя на практических занятиях перевод текстов на родной язык учащихся, с одной стороны позволяет лучше понять содержание прочитанного, а с другой - мешают усвоению лексического и грамматического материала.

При работе с научными текстами необходимо не только обращать внимание на то, как студенты-иностранцы узнают слова в тексте, запомнили их значение, но и как они владеют этой лексикой, и как они используют ее в речи. Поэтому так важно на практических занятиях применять лексические упражнения, направленные на активизацию изучаемых слов, чтобы пассивный лексический запас перешел в активный. Для этого студенты не только пересказывают отдельный фрагмент текста, но и обсуждают его, высказывают свою точку зрения на проблему. Эта работа также позволяет студентам-иностранцам лучше усвоить новые лексические единицы и грамматические конструкции научного стиля речи.

Отечественные методисты выделяют 3 вида чтения: поисковое, ознакомительное и изучающее. При поисковом чтении студент должен выяснить для себя, содержит ли данный текст нужную ему информацию или нет, определить, какие основные вопросы в нем рассматриваются. При таком виде чтении важно и понимание заголовков, подзаголовков, а также внешняя структура текста. Поисковое чтение предполагает ускоренный темп, так как читающий должен охватить целые абзацы, а не читать слово за словом, и при этом не использовать перевод для понимания прочитанного.
Ознакомительное чтение предполагает умение быстро уловить фрагмент текста, содержащий главную информацию. Этот вид чтения часто вызывает затруднения у студентов-иностранцев, т.к. недостаточное владение языком не позволяет им отличить главную информацию от второстепенной. Поэтому перед ознакомительным чтением преподаватель задает несколько вопросов, как бы вводя учащихся в тему.

Под изучающим чтением подразумевается полное понимание и осмысление текста. Студентам должны выявлять главную и второстепенную информацию, отвечать на вопросы по тексту, уметь дополнить высказывание, используя информацию из текста. Конечно, в тексте есть и незнакомые им слова, тогда приходит на помощь языковая догадка. На первом курсе принципы изучающего чтения используются больше всего.

Так как практические занятия в первом семестре в большей степени направлены на повторение трудных случаев русской грамматики и на усвоение профессиональной лексики и терминологии, студентам-иностранцам нетрудно определить синтаксические единицы, членить сложное предложение, понимать значение сложных слов и способы их образования. Но вместе с тем иностранные студенты при чтении научной литературы часто ошибаются, определяя грамматические формы, что ведет к неправильному пониманию предложения. Разбирая предложения, студенты-иностранцы легко определяют сказуемое, выраженное глаголом, так как этот член предложения, как правило, четко выражен. Верное определение субъекта и предиката способствует общему пониманию предложения. Нередко при разборе простого предложения студенты ошибочно принимают существительное, стоящее в косвенном падеже за субъект, а существительное в именительном падеже - за объект, что приводит к непониманию целого высказывания. Например: Путь к повышению к прочности бетона лежит через дробление материалов на мельчайшие частицы. Железобетонные конструкции способны принимать разные конструктивные и архитектурные формы. Студенты ошибочно принимают словосочетание мельчайшие частицы, конструктивные и архитектурные формы как субъект предложения, а слово путь, железобетонные конструкции выделяют как объект. При разборе ошибок преподаватель напоминает, что субъектом предложения, как правило, является только существительное, стоящее в именительном падеже.

Проводя работу над отдельным предложением текста, студенты должны уметь не только определять главные и второстепенные члены предложения, но и уметь задавать вопросы от главных слов к зависимым, определять, к какому слову относится причастный оборот, трансформировать простое предложение с причастиями в сложное.

При синтаксическом анализе обращается внимание студентов на порядок слов в предложении. Если после существительного стоит другое существительное, то, как 
правило, оно должно быть в форме родительного падежа, например: техника возведения высотных зданий; nрименение бетона; использование системы перекрестного вентилирования. Если студент ошибается в определении рода существительного, то слово записывается в именительном падеже, потом составляются словосочетания, используя падежные формы. Если же студент не знает значение предлога, то сначала объясняется значение глагола, далее записываются словосочетания, указывая глагольное управление, затем находится субъект, и только потом разъясняется целое высказывание.

Если существительное употреблено с предлогом, то объясняется значение предлога, выясняется, зависит ли предлог от глагола или от существительного, т.е. еще раз объясняется глагольное и именное управление. Например: для возведения стен использовали кирпич из керамики; элементы входят в конструкцию зданий; поток воздуха циркулирует между стеной и облицовкой.

Подробный синтаксический анализ проводится только в тех случаях, когда непонятна структура предложения, если же предложение понимается с первого прочтения, то анализ не нужен.

Беспереводному чтению предшествуют предтекстовые и притекстовые задания, включающие в себя работу с лексикой, представленной в тексте, а также упражнения на управление, согласование, осмысление незнакомых слов с помощью смысловой догадки, сравнений, сопоставлений по аналогии, образование сложных слов. Заранее составленные вопросы способствуют пониманию текста.

Предъявляя профессионально ориентированный текст, преподаватель должен быть уверен, что студентам-иностранцам понятна значительная часть лексики. Языковая догадка при беспереводном изучающем чтении очень важна, но она не является навыком, формирующимся автоматически. Студентами-иностранцами без труда узнаются иноязычные слова, например: интерьер, конструкции, габариты, деталь, изоляция, но это нельзя считать языковой догадкой. На практических занятиях языковой догадке уделяется большое внимание.
При первом прочтении нового текста по специальности студентам предлагается перевести часть текста, которая, по мнению преподавателя, может представить затруднения. Как правило, в этой части текста содержится главная информация. Разбирая данный фрагмент текста, преподавателем предлагается несколько заданий, направленных на снятие лексико-грамматических трудностей. Это могут быть грамматические задания на определение начальной формы слова, глагольное управление, трансформацию простых предложений с причастиями в сложные, а также лексические: нахождение синонимов или антонимов, перефразирование высказывания. Студенты-иностранцы, работая с профессиональными текстами, испытывают большие трудности, так как их лексический запас не позволяет им читать без словаря. Как показывает практика, лексический запас студентов различен и недостаточен для чтения неадаптированной профессиональной литературы. Именно здесь на помощь студентам приходит языковая догадка.

Проверить понимание прочитанного текста помогают вопросы, относящиеся не только главной информации, но и второстепенной. Например: что вы узнали из текста о ...? как автор определяет свое отношение к поставленной проблеме? в какой связи и тексте говорится об этой проблеме? Можно задавать и вопросы, ответы на которые в тексте не содержится.

После всех заданий, направленны на понимание текста, студенты приступают к составлению плана. Студентам-иностранцам, умеющим вычленять основную мысль в каждом абзаце, выделять основную и второстепенную информацию, бывает легче запомнить и воспроизвести текст.

Принципы изучающего беспереводного чтения направлены на обучение построения собственного высказывания на основе прочитанного научного текста.

Практические занятия в аудитории и домашнее чтение помогут студентам-иностранцам лучше понимать литературу по направлению подготовки. Принципы изучающего чтения помогут закрепить грамматические конструкции, используемые в научном стиле речи, а также способствуют лучшему пониманию литературы по специальности.

\section{ЛИТЕРАТУРА}

1. Е.И. Пассов, Н.Е Кузовлева. - Ростов н/Д: Феникс» М: Глосса-Пресс, 2010. - 640 с.

2. .К. Фоломкина. Некоторые вопросы обучения чтению на иностранном языке в неязыковом вузе. стр. 3-12. / Иностранные языки в высшей школе. Выпуск 6. Изд-во «Высшая школа» Москва 1971, с. 175

3. Пассов Е.И. Учебное пособие по методике обучения иностранным языкам / Воронеж : ВГПИ, 1975. - 283 с.;

4. Акишина А.А. Каган 0.Е. Учимся учить / 7-е изд. -М.: Русский язык. Курсы, 2010 -256с.

() Даниелян Мери Георгиевна (daniel_mg@list.ru). 